\title{
Integration of Individual Processes and Information Demand Patterns: A Conceptual Analysis
}

\author{
Michael Leyer ${ }^{1}$ and Kurt Sandkuhl ${ }^{2 *}$ \\ ${ }^{1}$ University of Rostock, Institute of Business Administration, Ulmenstr. 69, 18051 \\ Rostock, Germany \\ ${ }^{2}$ University of Rostock, Institute of Computer Science, Albert-Einstein-Str. 22, 18059 \\ Rostock, Germany \\ michael.leyer@uni-rostock.de, kurt.sandkuhl@uni-rostock.de
}

\begin{abstract}
Individuals need a variety of information when performing their personal processes. However, companies typically know little about the underlying individual demand patterns in these processes. Conceptualizing information demand patterns of individuals is expected to allow for using these as foundation to extend the traditional internal information logistic perspective of companies. Digital options could then be used to align individual and organizational information leading not only to new product and service offers, but also to new work structures in organizations. Thus, we extend prior literature regarding business process management and information logistics by highlighting how information demand patterns (IDP) have to be adapted to individual processes. Our exploratory approach is to demonstrate conceptually the conditions and implications of individual IDPs.

Keywords: Individual process model, information logistics, information demand analysis, information demand pattern.
\end{abstract}

\section{Relevance of Individual Processes}

Business process management (BPM) has received an enormous attention in research and industry during the last twenty years and is considered as a key technology to increase efficiency in organizations [1]. An important aspect within BPM is the distribution of information between employees in processes with divided responsibilities [2]. During the last decade, research in information logistics has been addressing the aspect of optimized information supply (see Section 3). Advantages attributed to information logistics (ILOG) are to avoid wrong decisions due to missing or incomplete information and to increase efficiency with regard to searching information [3].

\footnotetext{
* Corresponding author
}

(C) 2017 Michael Leyer and Kurt Sandkuhl. This is an open access article licensed under the Creative Commons Attribution License (http://creativecommons.org/licenses/by/4.0).

Reference: M. Leyer and K. Sandkuhl, "Integration of Individual Processes and Information Demand Patterns: A Conceptual Analysis," Complex Systems Informatics and Modeling Quarterly, CSIMQ, no. 13, pp. 61-72, 2017. Available: https://doi.org/10.7250/csimq.2017-13.04

Additional information. Author's ORCID iD: M. Leyer - orcid.org/0000-0001-9429-7770 and K. Sandkuhl - orcid.org/0000-0002-7431-8412. Article PII S225599221700077X. Article received: 2017 February 02. Accepted: 2017 October 2. Available online: 2017 December 29. 
In the past, both BPM and ILOG have predominantly taken an organizational perspective with BPM focusing on improving processes and ILOG on improving information flow for the roles in an organization. However, with an increasing penetration of IT, social media and mobile devices in basically all situations of private life, it becomes more and more important for companies to understand individual needs to improve processes [4], [5]. In the center of this understanding is the perspective on processes of individuals independently from an organizational role [6]. Modeling these individual processes is important from a marketing and service management perspective, as these contextualize the customers' behavior when selecting products and services which support their activities best [7]. Starting from the individual perspective provides new insights how customers behave beyond existing products and services.

In this article, we focus on integrating individual processes (IP) and information demand patterns (IDP) with the purpose of showing conceptual feasibility and motivating future work in the area. The research approach taken is an exploratory investigation with argumentative, deductive elements. The main contribution of the work is (1) to show the relevance of integrating IP and ILOG, (2) to identify which changes would be required in IDPs for implementing this integration and (3) to illustrate the integration based on an illustrative example.

These contributions can serve as a foundation to develop new opportunities for information logistics in companies. Individual processes can become the starting point for linking information between employees in a company and between companies. New digital applications can be developed that capture, store and use individual demand patterns to offer additional values for customers. At the same time, this integration of external information can lead to different structures in organizations in terms of collaboration between employees. The connection between employees will be based less on functional or process hierarchies but rather on the similarity of individual demand patterns. Thus, digital options can be used to form digitally connected and structured organizations not only internally but also closely to customers.

The article is organized as follows: The theoretical background of individual processes is described in Section 2. This is followed by the idea of information logistics and information demand patterns in Section 3. Section 4 contains the application of the transferring the concept of individual demand patterns on individual processes. In Section 5 an illustrative example is presented. The article concludes with a discussion and an outlook in Section 6.

\section{Individual Processes}

The simplest description of a process is that it is a connected series of activities [8]. Business processes are designed, measured, analyzed and controlled with typical goals of cycle time and cost reduction as well as quality improvement. The same can be done for individuals who also have processes [7]. During their daily life, individuals perform various activities which are triggered by life events [9]. Life events can be once in a lifetime (or rarely happening) occasions such as marriage, building a house or getting a child. However, also daily events can occur for an individual such as receiving parcels or meeting a friend on the street.

Processes of individuals resulting from such events differ from business processes as the goal is not to create value in the interest of a customer but to satisfy needs in the own interest [10], [11]. This change in perspective leads to several fundamental differences between business processes and individual processes. From an individual perspective, companies are not needed per se while companies rely on individuals buying products and services. Theoretically, individuals could perform all their activities without the support of any company. In reality individuals seek for support, but thus individuals are targeting organizations instead of the other way round [12]. The goal of performing activities is not to maximize a profit [13] but satisfaction. The subsequent value definition is implicit according to an individual's needs and not explicit according to corporate goals. As such, the predominant focus of activities is not 
deliver services or products demanded which requires a different categorization of individual processes compared to business processes.

However, the basic idea of separating processes into primary (value creating resp. satisfaction of needs) and secondary (value enabling resp. enabling of need fulfillment) [13] can be applied [14]. Following this line of argumentation, [15] presents a generic individual value chain (Figure 1) as corresponding element to the business value chain from [13].

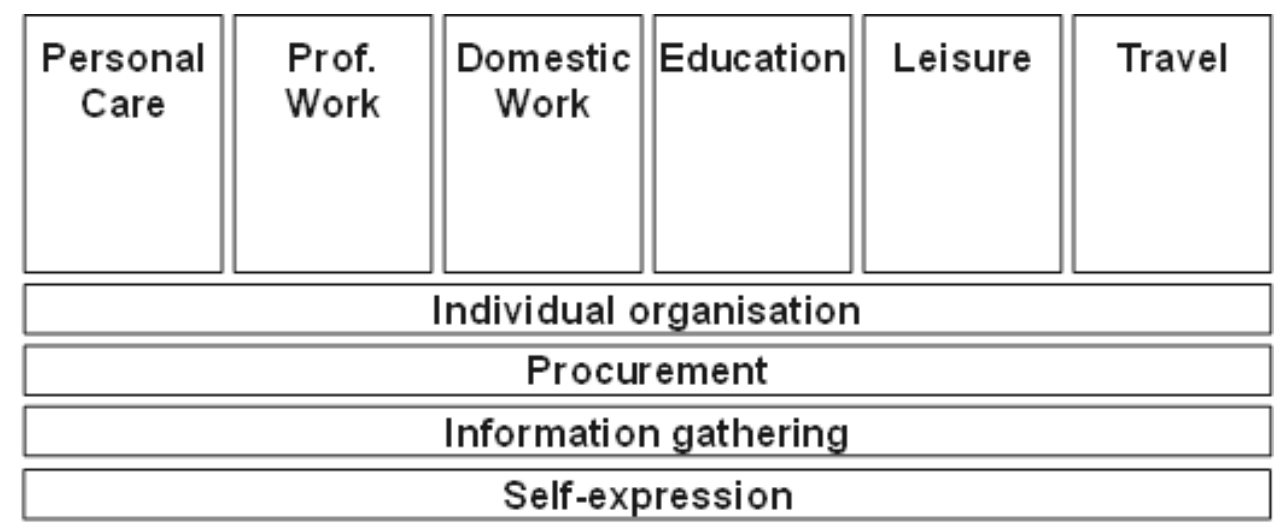

Figure 1. Generic Individual Value Chain [15]

The generic individual value chain describes primary activities differentiated into six components in which processes can be grouped. This differentiation is based on large-scale empirical data from ten European countries covering 82.095 individuals as well as from the United States covering over 159.000 individuals. Activities are gathered within this panel from individuals of every age and profession. Performing these primary activities adds directly to the satisfaction of needs. They can be described as follows [15]:

- Personal care: These activities are performed by individuals with the aim to improve or sustain physical and psychic health. Examples are eating or visiting a psychologist.

- Education: This category covers activities in which an individual gains new knowledge. Examples are learning in school or attending an advanced training seminar.

- Professional work: Within this category all professional work for which an individual gets paid is bundled. Examples are a regular job or being self-employed.

- Domestic work: Every activity done at home such as cleaning clothes or preparing meals.

- Leisure: These activities are performed with the aim of entertainment. Examples are meeting friends or going to the movies.

- Travel: This category covers every activity which moves an individual from a to b. Examples are going by bus or walking.

In addition, value enabling activities deduced from transaction cost theory [16] and social exchange theory [17] are necessary to support the primary activities:

- Individual organization: In order to perform the primary activities some organization is necessary. This includes personal scheduling, making appointments or organizing personal financials.

- Procurement: If an individual needs a product or service to perform its activities, procurement has to take place. This class of activities covers the procedure of procurement such as buying a swim suit, getting food or using a delivery service.

- Information gathering: Much information is required to perform activities which are covered by this category of activities. Examples are searching for the nearest gas station or when a concert takes place. 
- Self-expression: Individuals want to share their experiences in their life, i.e. their primary activities performed. Examples are posting status updates on Facebook or telling colleagues about the last holiday.

Every activity of individuals can be assigned to one of the categories to structure individual processes [15]. An important aspect within this framework is the category "Information gathering" which is required as enabling activity for almost every primary activity [4]. How the required information can be modeled in terms of patterns and be differentiated in the primary categories is discussed in the reminder of the article.

\section{Information Logistics and Information Demand Patterns}

Accurate and readily available information is indispensable in problem solving, decisionmaking, and knowledge-intensive work. Studies on information use show that information overload is perceived as a problem in organizations and enterprises [18] as well as information shortage. For more than a decade the field of ILOG has been addressing the above mentioned challenge by using principles from material logistics, like just-in-time delivery, for the provision of information. ILOG explores, develops, and implements concepts, methods, technologies, and solutions for the above mentioned purpose. Contemporary research work in ILOG includes

- a method for information demand analysis in an enterprise context [3],

- patterns of information demand for efficiently constructing solutions (see below),

- a framework for ILOG in business intelligence [19],

- technologies for matching information demand and content [20],

- applications for tele-medicine [21] or media industries [22].

The general idea of IDPs is similar to most pattern developments in computer science: to facilitate reuse of proven knowledge about solutions to engineering problems by capturing the core principle and structure of the solution independently from an application case. In this article, the term IDP is defined as follows [23]: An IDP addresses a recurring information flow problem that arises for specific roles and work situations in an enterprise, and presents a conceptual solution to it.

An IDP consists of a number of elements used for describing the pattern [24]:

- The pattern name usually is the name of the role the pattern addresses.

- The organizational context explains where the pattern is useful. This context description identifies the application domain or the specific departments or functions in an organization forming the context for pattern definition.

- The problems of a role are identified. The tasks and responsibilities a certain role has are described in order to identify and discuss the challenges and problems, which this role usually faces in the defined organizational context.

- The conceptual solution describes how to solve the addressed problem. This includes the information demand of the role, which is related to the tasks and responsibilities, a timeline indicating the points in time when the information should be available, and quality criteria for the different elements of the information demand. These criteria include the general importance of the information, the importance of receiving the information completely and with high accuracy, and the importance of timely or real-time information supply.

- The effects that play in using the proposed solution are described. Missing or late information might affect the possibility of the role to complete its task and responsibilities. IDPs include several kinds of effects: potential economic consequences; time/efficiency effects; effects on increasing or reducing the quality of the work results; effects on the motivation of the role responsible; learning and experience effects; effects from a customer perspective. 


\section{Information Demand Patterns in Individual Processes}

One of the initial motivations for developing IDP was the observation that in many organizational contexts a process-centric perspective, as e.g. manifested in business process management, does not fully reflect the operational needs of organizational roles when it comes to information supply [25]. An information-centric perspective, as expressed in IDP, was considered as a valuable complement or sometimes even as more important for an organizational role than the process view [3]. Thus, we argue that even for individuals and their needs it might be beneficial to consider both, a process and an information demand perspective, and to integrate both aspects.

This Section investigates whether it is feasible and makes sense to apply the concept of IDP in IP and what adaptations would be needed. For this purpose, we need to discuss which changes (if any) are required in the structure of IDP (Section 4.1), what implications the changes in IDP have for the processes of developing such patterns (Section 4.2) and how IDP adapted for IP can be used (Section 5). Conceptually, the current focus of IDP on a specific organizational role has to be replaced by a focus on an individual which has no clear role definition in terms of responsibilities for organizational tasks or organizational activities.

\subsection{Adaptation of IDP Structure for Individual Processes}

IDP adapted for IP would have the purpose to establish an information supply to the individual that meets his/her demands resulting from the actual process status at a given point in time. With this in mind, we investigated two aspects for each element of the IDP structure presented in Section 2:

- Is the element still relevant for specifying the information demand of an individual? If not, is there is a need for replacing the element?

- Can the element be derived from or defined based on the individual processes of an individual? How?

The result of this investigation is shown in Table 1. The table shows that most elements of IDP remain relevant and can be derived from individual processes, like the actual information demand, its quality criteria or most of the effects. The most important adaptation of the IDP structure is required for "organizational context" as individuals obviously have responsibilities and tasks that are not connected to an organizational role. However, to define in which "context" of an individual the information demand occurs still is crucial which indicates that a replacement for this element is required. One possible source for identifying relevant aspects of the individual "context" is the generic value chain proposed in Section 3 and depicted in Figure 1. When analyzing this value chain, secondary activities in the category "self-expression" which are not focusing on the individuals "inner" view but are putting the individual in a context (the social communication part) can be identified. Thus, we propose to replace organizational context with social context. Furthermore, the "timeline" element of IDP seems to be superfluous as the individual processes (processes are sequences of activities) already cover this aspect. The effects on "customers" only seem relevant for individuals if interpreted as "cooperating actors", i.e. other individuals or organizations who would be affected by missing or delayed information supply to the individual. Effects of missing or delayed information on the own "motivation" of an individual need further investigation before deciding on relevance of this element. 
Table 1. Analysis of IDP structure regarding fitness for IP

\begin{tabular}{|c|c|c|c|}
\hline \multirow{2}{*}{\multicolumn{2}{|c|}{$\begin{array}{l}\text { IDP element } \\
\text { Pattern name }\end{array}$}} & Relevant for IP? Why? & $\begin{array}{l}\text { Derivable from individual processes? } \\
\text { How? }\end{array}$ \\
\hline & & $\begin{array}{l}\text { YES - pattern have to be } \\
\text { identifiable }\end{array}$ & YES - use "situation" of individual \\
\hline \multirow[t]{2}{*}{$\begin{array}{l}\text { Organizational } \\
\text { context }\end{array}$} & $\begin{array}{l}\text { Responsibility } \\
\text { of role }\end{array}$ & $\begin{array}{l}\text { NO }- \text { replace with social } \\
\text { context }\end{array}$ & $\begin{array}{l}\text { YES - analyze "self-expression" in } \\
\text { individual processes }\end{array}$ \\
\hline & Tasks of role & $\begin{array}{l}\mathrm{NO} \text { - replace with individual } \\
\text { processes }\end{array}$ & YES - use categories of individual processes \\
\hline \multicolumn{2}{|c|}{ Information demand } & $\begin{array}{l}\text { YES - making the information } \\
\text { demand explicit is key } \\
\text { purpose }\end{array}$ & $\begin{array}{l}\text { YES - analyze "information gathering" in } \\
\text { individual processes }\end{array}$ \\
\hline \multirow[t]{3}{*}{$\begin{array}{l}\text { Quality } \\
\text { criteria }\end{array}$} & Accuracy & $\begin{array}{l}\text { YES - accuracy of } \\
\text { information can be important } \\
\text { for individuals }\end{array}$ & \multirow[t]{3}{*}{$\begin{array}{l}\text { YES - for each information demand, } \\
\text { analyze individual's view on quality } \\
\text { requirements }\end{array}$} \\
\hline & Timeliness & $\begin{array}{l}\text { YES } \quad-\text { timeliness of } \\
\text { information can be important } \\
\text { for individuals }\end{array}$ & \\
\hline & Completeness & $\begin{array}{l}\text { YES - completeness can be } \\
\text { important for individuals }\end{array}$ & \\
\hline \multicolumn{2}{|l|}{ Timeline } & $\begin{array}{l}\text { NO - given by the actual } \\
\text { process }\end{array}$ & $\mathrm{NO}$ - given by the actual process \\
\hline \multirow[t]{5}{*}{ Effects } & Economic & $\begin{array}{l}\text { YES - economic effects are } \\
\text { relevant when providing } \\
\text { information }\end{array}$ & \multirow[t]{3}{*}{$\begin{array}{l}\text { YES - for each information demand, } \\
\text { analyze impact on processes }\end{array}$} \\
\hline & Process & $\begin{array}{l}\text { YES - if interpreted as effects } \\
\text { on process duration, such } \\
\text { effects are relevant }\end{array}$ & \\
\hline & Quality & $\begin{array}{l}\text { YES - if interpreted as effects } \\
\text { on the result quality such } \\
\text { effects are relevant }\end{array}$ & \\
\hline & Motivation & $\begin{array}{l}\text { YES - if interpreted as } \\
\text { affecting } \\
\text { motivation, such effects can } \\
\text { be relevant }\end{array}$ & YES - identifying individual needs \\
\hline & Customer & $\begin{array}{l}\text { YES - if interpreted as } \\
\text { cooperating actors }\end{array}$ & $\begin{array}{l}\text { YES - Individual process execution can be } \\
\text { available for other individuals who perceive } \\
\text { increase of need satisfaction }\end{array}$ \\
\hline
\end{tabular}

\subsection{Implications for Information Demand Analysis}

Starting point for the development of an IDP usually is an information demand analysis (IDA), which consists of the following steps. More details and an example are available in [26]:

- Scoping is the process of defining the area of analysis and is done with the purpose of selecting parts of an organization. This phase also includes the identification of the roles relevant for the continued information demand analysis.

- Information demand context modeling is mainly performed through joint modeling seminars with domain experts knowledgeable regarding the information demand of the identified 
roles during scoping. The conceptual focus is on information demand within a defined scope. The key to context modeling is to identify the interrelationship between roles, tasks, resources and information.

- Information Demand Context Analysis: once the necessary knowledge about the information demand contexts is obtained it usually has to be analyzed regarding change needs in the information supply as such and in the way (organizational and technical) the information is provided. The result of the analysis is an initial concept for the future situation. Furthermore, the information demand for each individual role is captured in a structured way using the same elements that are also part of IDP (see Section 3), i.e. the organizational context of the role, the tasks and responsibilities, the information demand, the quality criteria of the information demands, and the effects of not receiving information.

- Design of information supply solution: the initial ideas for organizational and technical changes and improvements are elaborated. The result is a "blueprint" for implementing required changes.

- Implementation: the implementation of the "blueprint" defined in the previous step is not part of the information demand analysis method, as this usually requires organizational change, information system or software engineering efforts which are supported by existing methods.

One of the results of the above IDA, in particular of the step "information demand context analysis", is the documentation of the information demand for the organizational roles included in the scope. If the identified information demand is specific for the roles in more than one enterprise but and be considered as typical for a category of enterprises, IDP can be developed. IDP development can be done in two different ways: (1) by an expert who can define an abstraction from the specific enterprise considered in the IDA, i.e. the information demand descriptions are generalized by the expert, or (2) by performing additional IDA in more enterprises from the same domain with the same roles; the results of these different IDAs are analyzed and the common elements in all IDAs are integrated into a pattern.

The general structure and activities of the IDA process can be maintained even for a changed structure of IDP. However, the focus in every activity of the process has to be changed from organizational roles to individual processes and demands, e.g., in scoping, the decision has to be made which individual processes should be in focus; in context analysis, the individuals having the demand have to be involved instead of experts from the organization, thus social networks analysis will gain more importance.

\section{Illustrative Example}

A variety of activities are carried out by individuals. Picking out one example shall serve to demonstrate the implications of the proposed conceptualization. Imagine the situation of a man in the age of 55 who had a stroke, was in hospital and is now in the rehabilitation process. Figure 1 depicts a typical day of his life.

The information demand for this case was derived from previous work for hospitals and stroke care units which was directed towards analyzing the treatment and rehabilitation processes for stroke patients with a focus on inter-organizational information flow and coordination [27]. When analyzing this work it became clear that rehabilitation of stroke patients involves a variety of activities for the individual patient and various stakeholders. Additional individual activities not visible in the case material were identified based on the generic value chain depicted in Figure 2. As it can be seen within the figure, there are many providers involved in the activities of this individual. These typically offer their services independently from each other and information is only shared partially through the described individual. In Section 5.1 we will introduce an information demand pattern for the individual, in Section 5.2 we will illustrate the use of this pattern in customer service. 


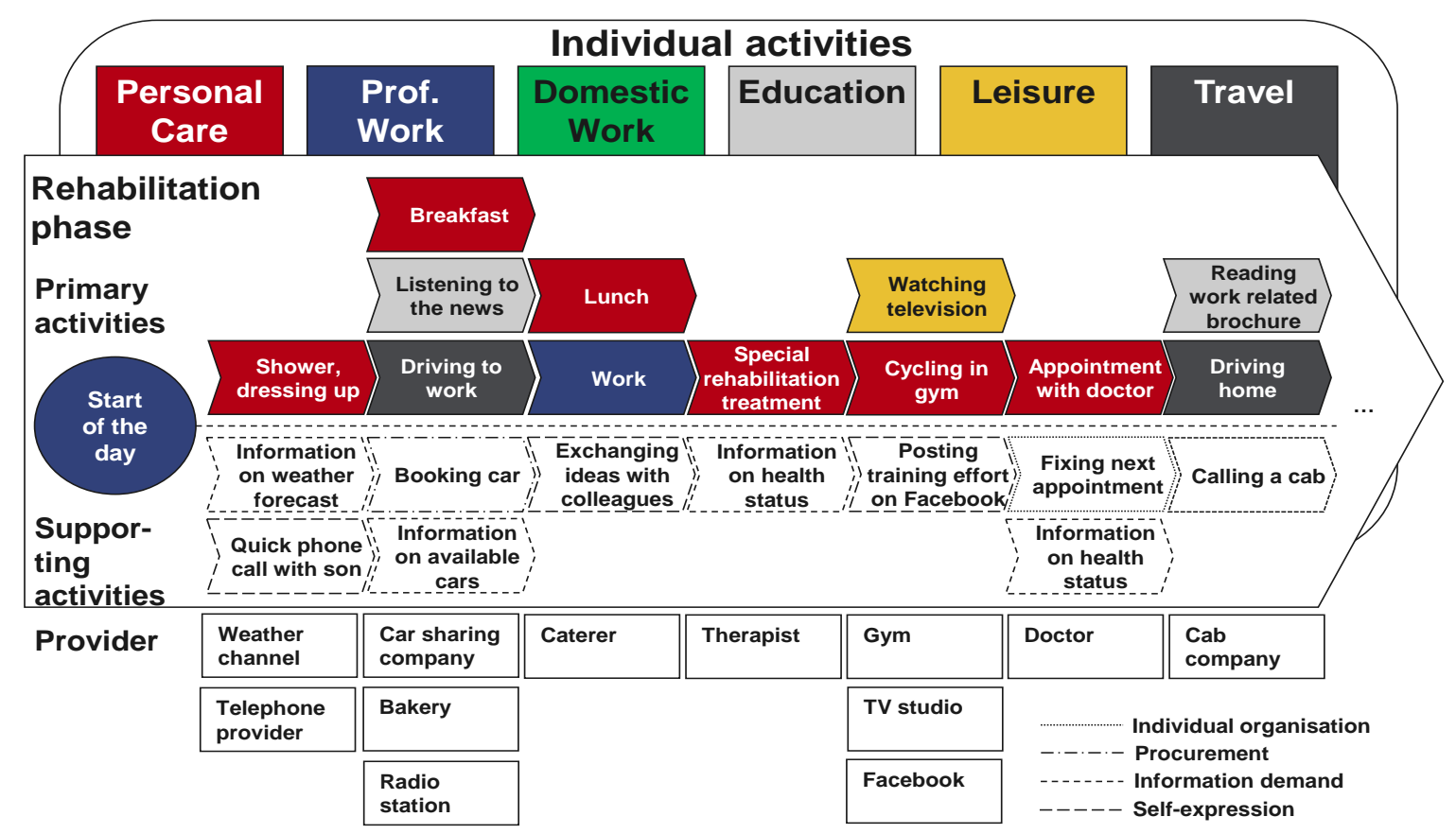

Figure 2. Example of linking providers and individual processes

\subsection{Information Demand Pattern}

The information demand in the rehabilitation process can be captured with the adapted IDP structure introduced in Section 4.1. For brevity reason, we will only show social context, information demand and quality criteria excerpts of this IDP:

Social Context: The IDP supports an individual person in a rehabilitation situation with the aim to facilitate an integrated view on information about relevant medical, therapeutic, nutrition and work aspects, which are mutually dependent. The problem addressed is including the planning of sequence and timing of different activities, alignment of medical and nutrition perspectives and coordination between different actors from professional and social context of the individual.

Information Demand: The information demand is based on the individual's processes and their integration. The information demand for the social context consists of:

- Implication from the individual's medical status for therapy (e.g. the kind of training, load, level of control, focus of activity), catering (e.g. diet requirements, timing of meals, logistics) and work (e.g. acceptable kinds of work, workload, number of hours/day, integration) and their integration.

- Existing requirements from legislation or policies to comply with given the status and progress of rehabilitation (e.g. clinical treatment paths, health insurance policies)

- Changes in medical status affecting the future therapy, catering or work.

- Contributions from relatives and friends of the individual (e.g. support in transfer between therapy elements, logistics of medication, etc.).

- Schedule constraints originating from meetings and obligations at the workplace, availability of relatives and friends, own plans and fixed dates.

The quality criteria for the above information demand uses three levels, i.e. for each information demand, the quality required is defined as follows:

- Decisive: you cannot manage without this information.

- High: it is important to have this information, but in worst case you complete the task without it. 
- Nice to have: you will manage without this information, but this will affect the result.

For the pattern, the quality criteria are summarized in a Table 2, which includes the information demand and the importance to get the information accurately, as soon as possible and completely.

Table 2. Quality criteria for example pattern

\begin{tabular}{|l|c|c|c|}
\hline & Accurate & $\begin{array}{c}\text { As early as } \\
\text { possible }\end{array}$ & Complete \\
\hline Implications from medical status & decisive & high & decisive \\
\hline Requirements from legislation / policies & high & high & high \\
\hline Changes in medical status & decisive & decisive & decisive \\
\hline Contributions from relatives and friends & high & nice to have & high \\
\hline Schedule constraints & high & nice to have & high \\
\hline
\end{tabular}

\subsection{IDP Use in Customer Assistance}

In order to illustrate the use and benefits of IDP in integration with IP, this section will apply the IDP presented in Section 5.1 in the area of customer information assistance. The IDP identified the information demand of an individual person in the context of rehabilitation. The different information demands are interesting for service providers related to rehabilitation since they can be used for offering and tailoring services. Furthermore, information relevant for several service providers show cross-sales potential or potential integration of value chains.

In each cell of Table 3, relevance of information for a service provider is indicated with an "R:" followed by "yes" or "no"; whether the service provider has access is indicated with an "A:" followed by "yes", "no" or that the information is only "partly" available. Table 3 shows that there is an overlap between information demand for the rehabilitation center and the gym provider. Information related to the health status is decisive for determining what rehab treatment is required and the health insurance policy defines which treatment will be paid. At the same time, the gym can deduct information from the health status and the insurance policy what the patient is allowed to book as additional service. As the health status information is available to the rehab center in order to be able to plan the treatment, but usually not to the gym provider, the rehab center would have to be the initiator of a cross-sales activity with the gym. Only when both cooperate, the two service providers may create an offer exploiting the economic potential of the patient (or its insurance policy) in an integrated way.

The above example is based on a correlation between two information demands that probably exists for many stroke patients, i.e. this cross-sales or service bundle potential for improved customer service can be identified by analyzing the IDP only - without the actual individual processes of the patient. But, there are also many examples where IDP in combination with the IP are required to improve customer service: In our example, let us assume that the health condition of the 55 year old man is improving. This week's rehab focuses on handling specific objects and selected body positions will be extended during next week towards mobility and endurance. This means that from the next week, a special gym training accompanying the rehab treatment is possible. To reach his favorite gym, the patient would need a car but his own car is not suitable in the current health status since it does not have automatic gear shift. For the first two days next week this would not be a problem because his sister can give him a ride to the gym, but she is on a business trip during the second half of the week, which means that for this time period he would need a rental car. The special training in the gym will be paid by the health insurance if a qualified trainer is available. This trainer is not a full-time employee of the gym, i.e. the schedule of our patient (and during the first days the schedule of his sister) and the trainer have to be synchronized. 
Table 3. Relevance of Information Demand for Service Providers

\begin{tabular}{|c|c|c|c|}
\hline $\begin{array}{ll}\text { Service } \\
\text { Provider }\end{array}$ & $\begin{array}{l}\text { Rehab. } \\
\text { Center }\end{array}$ & Gym. provider & Car rental \\
\hline Implications from medical status & $\begin{array}{l}\text { A: yes } \\
R: \text { yes }\end{array}$ & $\begin{array}{l}\text { A: no } \\
\text { R: yes }\end{array}$ & $\begin{array}{l}\text { A: no } \\
\text { R: yes }\end{array}$ \\
\hline Requirements from legislation / policies & $\begin{array}{l}\text { A: yes } \\
R: \text { yes }\end{array}$ & $\begin{array}{l}\text { A: no } \\
\text { R: yes }\end{array}$ & $\begin{array}{l}\text { A: no } \\
\text { R: no }\end{array}$ \\
\hline Changes in medical status & $\begin{array}{l}\text { A: yes } \\
\text { R: yes }\end{array}$ & $\begin{array}{l}\text { A: no } \\
\text { R: yes }\end{array}$ & $\begin{array}{l}\text { A: no } \\
\text { R: no }\end{array}$ \\
\hline Contributions from relatives and friends & $\begin{array}{l}\text { A: no } \\
\text { R: no }\end{array}$ & $\begin{array}{l}\text { A: partly } \\
\text { R: yes }\end{array}$ & $\begin{array}{l}\text { A: no } \\
\text { R: yes }\end{array}$ \\
\hline Schedule Constraints & $\begin{array}{c}\text { A: partly } \\
\text { R: yes }\end{array}$ & $\begin{array}{c}\text { A: partly } \\
\text { R: yes }\end{array}$ & $\begin{array}{l}\text { A: no } \\
\text { R: yes }\end{array}$ \\
\hline
\end{tabular}

The example illustrates that rehab center and/or gym could extend the service bundle towards a car rental company if they would have access to information about the contributions from relatives and schedule constraints. Since rehab center and gym both have a customer relationship to our patient, they even may have access to part of this information based on the scheduled treatments/trainings and the motivation given by the patient for booking certain dates and times. However, this information about schedule and involvement of relatives usually would go unnoticed at the service providers. With an integration of a support of individual processes (generating the required information while supporting the individual) and information demand patterns (defining the interrelation between the information), this type of conclusions and additional customers services would be possible.

\section{Conclusions and Outlook}

Application of the IDP structure in the illustrative example reveals an important difference between IDP adapted for individuals and organizational IDP: The adapted IDP always has to include different processes or what in organizational context would be information demand of different roles. This makes the adapted IDP more a pattern for a situation characterized by different dimensions of information demand than the conventional IDPs that include only the dimension of exactly one organizational role.

Our conceptualization can serve as foundation for the development of new information management systems connecting customers and companies. It starts with individual information of customers and can be expanded to link information of employees in different parts of a company and also across companies. Especially the possibilities of digital mobile solutions can be used to connect customer and company information using the described information patterns. Such information can be provided by individuals in their calendar apps of their smartphones or in apps of providers. Employees can then be granted access and provide solutions by bringing in their expertise. Such information can be shared with the customer, and with everyone involved in the individual process. Work could then be distributed according to similarity of individual information demand patterns. Thus, starting point according to the proposed conceptualization should be individual information demand patterns.

One of the limitations of this article is that the analysis of the pattern structure in Section 4.1 and the definition of the example in Section 5 were only based on the experiences of the researchers involved. Similarly to the development of IDP and information demand analysis where an extensive study and theory development was performed [28], these aspects would need more thorough empirical grounding.

The possibility to adapt IDP structure to IP has been demonstrated from a conceptual perspective (Section. 4) and illustrated in an example (Section 5). Despite this initial "proof-of- 
principle" some fundamental aspects need discussion and further investigation. One aspect is whether the adapted IDP structure still can be considered a pattern. Patterns are meant to represent the core principles of a solution typical for a class of problems. We strongly believe that it is possible to find recurring information demands for different individuals in the same situation, i.e. to identify patterns for individuals. However, this aspect needs further investigation. In addition, the transition from the presented concept to specific implementations requires methods and tools for various tasks, including how to capture, store and use individual information, and to select information matching to the actual context of the individual [29]. Also, it should be considered how to integrate privacy issues of individuals in assistance systems and how to integrate legal aspects with regard to privacy. Another aspect is whether IDP for individuals really represent a shift in perspective in ILOG or just leads "back to the roots". Early work in ILOG in many cases addressed individuals and not roles, e.g. when designing situationbased message supply. From this early work, inspiration might come how to improve adapted IDP. Going beyond ILOG, there should be further work on positioning the approach with regard to potential differences between business processes and individual processes focusing on aspects like process hierarchies, decision models, and decision-support systems. Finally, there has to be further research on how this perspective leads to changes in organizations in terms of shaping work distribution and organizational structures. Beyond that it should be explored how digital solutions can be adapted to fully support an integrated individual and organizational information logistic system.

\section{References}

[1] D. Nadarajah and S.L.S.A. Kadir, "A Review of the Importance of Business Process Management in Achieving Sustainable Competitive Advantage," The TQM Journal, vol. 26, no. 5, pp. 522-531, 2014. Available: https://doi.org/10.1108/TQM-01-2013-0008

[2] W.J. Hopp, and M.L. Spearman, “To Pull or Not to Pull. What Is the Question?” Manufacturing \& Service Operations Management, vol. 6, no. 2, pp. 133-148, 2004. Available: https://doi.org/10.1287/msom.1030.0028

[3] M. Lundqvist, E. Holmquist, K. Sandkuhl, U. Seigerroth, and J. Strandesjö, "Information Demand Context Modelling for Improved Information Flow. Experiences and Practices," The practice of enterprise modeling, pp. 8-22, 2009.

[4] F.Y.M. Cheung and W.M. To, "Do Task- and Relation-Oriented Customers Co-Create a Better Quality of Service? An Empirical Study of Customer-Dominant Logic," Management Decision, vol. 53, no. 1, pp. 179197, 2015. Available: https://doi.org/10.1108/MD-05-2014-0252

[5] K. Heinonen, T. Strandvik, and P. Voima, "Customer Dominant Value Formation in Service," European Business Review, vol. 25, no. 2, pp. 104-123, 2013. Available: https://doi.org/10.1108/09555341311302639

[6] J. Wind, and A. Rangaswamy, "Customerization. The Next Revolution in Mass Customization," Journal of Interactive Marketing, vol. 15, no. 1, pp. 13-32, 2001. Available: https://doi.org/10.1002/15206653(200124)15:1<13::AID-DIR1001>3.0.CO;2-\#

[7] K.-J. Mickelsson, "Customer Activity in Service,” Journal of Service Management, vol. 24, no. 5, pp. 534552, 2013. Available: https://doi.org/10.1108/JOSM-04-2013-0095

[8] T.H. Davenport and J.E. Short, "The New Industrial Engineering. Information Technology and Business Process Redesign," Sloan Management Review, vol. 31, no. 4, pp. 11-27, 1990.

[9] B.K. Brenner, "Life-Event Segmenting Offers Optimization of Benefit Effectiveness," Journal of financial service professionals, vol. 63, no. 3, pp. 26-29, 2009.

[10] T. Eichentopf, M. Kleinaltenkamp and J. Van Stiphout, "Modelling Customer Process Activities in Interactive Value Creation," Journal of Service Management, vol. 22, no. 5, pp. 650-663, 2011. Available: https://doi.org/10.1108/09564231111174997

[11] C. Tynan, S. Mckechnie and S. Hartley, "Interpreting Value in the Customer Service Experience Using Customer-Dominant Logic," Journal of Marketing Management, vol. 30, no. 9-10, pp. 1058-1081, 2014. Available: https://doi.org/10.1080/0267257X.2014.934269 
[12] R.A. Lindau, “Automatic Data Capture and Its Impact on Productivity," International Journal of Production Economics, vol. 52, no. 1-2, pp. 91-103, 1997. Available: https://doi.org/10.1016/S0925-5273(96)00046-1

[13] M.E. Porter, Competitive Advantage. Creating and Sustaining Superior Performance, Free Press, New York, 1985.

[14] K. Heinonen, T. Strandvik, K.-J. Mickelsson, B. Edvardsson, E. Sundström and P. Andersson, “A CustomerDominant Logic of Service," Journal of Service Management, vol. 21, no. 4, pp. 531-548, 2010. Available: https://doi.org/10.1108/09564231011066088

[15] M. Leyer, D. Kronsbein and M. Rosemann, Individual Process Management (Ipm). A Fundamental Shift from Organizations to Individuals in Strategic Positioning, University of Rostock, Rostock, 2015.

[16] O.E. Williamson, The Economic Institutions of Capitalism. Firms, Markets, Relational Contracting, Free Press, New York, 1985.

[17] R. Cropanzano and M.S. Mitchell, "Social Exchange Theory. An Interdisciplinary Review," Journal of Management, vol. 31, no. 6, pp. 874-900, 2005. Available: https://doi.org/10.1177/0149206305279602

[18] A. Öhgren and K. Sandkuhl, "Information Overload in Industrial Enterprises. Results of an Empirical Investigation," 2nd European Conference on Information Management and Evaluation, pp. 343-350, 2008.

[19] B. Dinter and R. Winter, "Information Logistics Strategy-Analysis of Current Practices and Proposal of a Framework", Proceedings of the 42nd Hawaii International Conference on System Sciences, pp. 1-10, 2009. Available: https://doi.org/10.1109/HICSS.2009.253

[20] F. Lin and K. Sandkuhl, "A New Expanding Tree Ontology Matching Method,” On the move to meaningful internet systems 2007. OTM $2007 \quad$ Workshops, pp. $1329-1337, \quad 2007$. Available: https://doi.org/10.1007/978-3-540-76890-6_61

[21] S. Meister and V. Stahlmann, "Telemedial Ilog Listeners. Information Logistics Processing of Telemedical Values Using Cep and H17," Ambient Assisted Living, pp. 245-259, 2012. Available: https://doi.org/10.1007/978-3-642-27491-6_18

[22] A. Billig, E. Blomqvist and F. Lin, "Semantic Matching Based on Enterprise Ontologies," Proceedings of the 6th International Conference on Ontologies, DataBases, and Applications of Semantics, pp. 1161-1168, 2007. Available: https://doi.org/10.1007/978-3-540-76848-7_76

[23] K. Sandkuhl, "Supporting Collaborative Engineering with Information Supply Patterns," Proceedings of the 18th Euromicro Conference on Parallel, Distributed and Network-based Processing, pp. 375-384, 2010. Available: https://doi.org/10.1109/PDP.2010.88

[24] K. Sandkuhl, "Improving Engineering Change Management with Information Demand Patterns," 8th International Conference on Product Lifecycle Management, pp. 47-58, 2011.

[25] M. Jandinger, "On a Need to Know Basis: A Conceptual and Methodological Framework for Modelling and Analysis of Information Demand in an Enterprise Context," Doctoral dissertation, Linköping University, 2016.

[26] M. Lundqvist, K. Sandkuhl and U. Seigerroth, "Modelling Information Demand in an Enterprise Context. Method, Notation, and Lessons Learned," in Krogstie, J., 'ed.' Frameworks for Developing Efficient Information Systems: Models, Theory, and Practice, IGI Publishing, Hershey, pp. 77-98, 2013. Available: https://doi.org/10.4018/jismd.2011070104

[27] K. Sandkuhl and A. Carstensen, "Web-Based Coordination Support in Care Planning," 32nd Euromicro Conference on Software Engineering and Advanced Applications, pp. 464-471, 2006. Available: https://doi.org/10.1109/EUROMICRO.2006.67

[28] M. Lundqvist, Information Demand and Use. Improving Information Flow within Small-Scale Business Contexts, Linköping University, Linköping, 2007.

[29] F. Lin, J. Butters, K. Sandkuhl and F. Ciravegna, "Context-Based Ontology Matching. Concept and Application Cases," IEEE 10th International Conference on Computer and Information Technology (CIT), pp. 1292-1298, 2010. Available: https://doi.org/10.1109/CIT.2010.233 